\title{
Effect of pressure and temperature variations on FEM prediction of deformation during extrusion
}

\section{Flitta and T. Sheppard*}

The extrusion process is complex, involving interaction between the process variables and the material's high temperature properties and is typically conducted at relatively high temperatures because the lower flow stress of the material permits larger section reductions to be achieved. This lowers the power requirements and processing times. Temperature is, perhaps, the most important parameter in extrusion. The flow stress is reduced if the temperature is increased and deformation is, therefore, easier, but at the same time, the maximum extrusion speed is reduced because localised temperatures must be well below any incipient melting temperature. The present investigation focuses on the evolution of the temperature in the billet from upsetting and until the end of the extrusion cycle is reached. The extrusion pressure and the temperature rise are predicted and the pressure-displacement trace and the events which take place in the deformed material during the extrusion process are also simulated. The simulation is compared with data obtained from an experimental extrusion press. All simulations are performed with the implicit finite element code FORGE2. A comparison with experiments is made to validate the predicted temperatures readings from FORGE2 to ensure that the numerical discretisation provides a true simulation of the process. It was found that the extrusion parameters (friction, heat transfer, etc.) are significantly influenced by the temperature gradients produced in the billet during transfer to the container, and after upsetting in the container. These parameters are thus clearly extremely sensitive input data when attempting to simulate the extrusion process.

\section{Introduction}

It is recognised that during extrusion the deformation energy is converted into heat, thereby increasing the temperature of the extrudate and in turn affecting the microstructure and mechanical properties. The increase in temperature during deformation also affects the temperature of the extrudate.

The basic process of extrusion is well described as a thermomechanical event in a recent text book, ${ }^{1}$ which indicates that the mathematical description of the process is still largely semi-empirical. However, since the publication of this book there have been significant advances in numerical analysis. The process variables have a large effect on the mechanical properties and surface quality of the extrudate. Knowledge of the initial billet temperature, the strain rate, flow stress of the working material, and extrusion ratio are required if correct and economical use is to be made of costly

Bournemouth University, Studland House, 12 Christchurch Road, Bournemouth, BH1 3NA, Dorset, UK

*Correponding author, email tsheppar@bournemouth.ac.uk extrusion facilities. Theoretically, the process variables which may be controlled are the extrusion ratio $R$, the ram speed $V$, and the initial extrusion temperature $T$. The possible range of these parameters is determined by alloy composition and the homogenisation treatment preceding extrusion. Customer specification and press capacity generally fix the extrusion ratio so that the temperature and speed become the major controllable parameters.

The force required for extrusion depends on the flow stress of the billet material, the extrusion ratio, the friction condition at the billet/container interface, the friction condition at the die/material interface, and other process variables, such as initial billet temperature and speed of extrusion. Extrusion can become impossible or can yield an unsatisfactory product when the load required exceeds the capacity of the press available or when the temperature of the extrusion exceeds the solidus temperature of the alloy. The extrusion temperature, like speed, has implications for the process other than its effect on pressure. The forces during extrusion are predominantly compressive, thus permitting high homologous working temperatures. Thus, the 


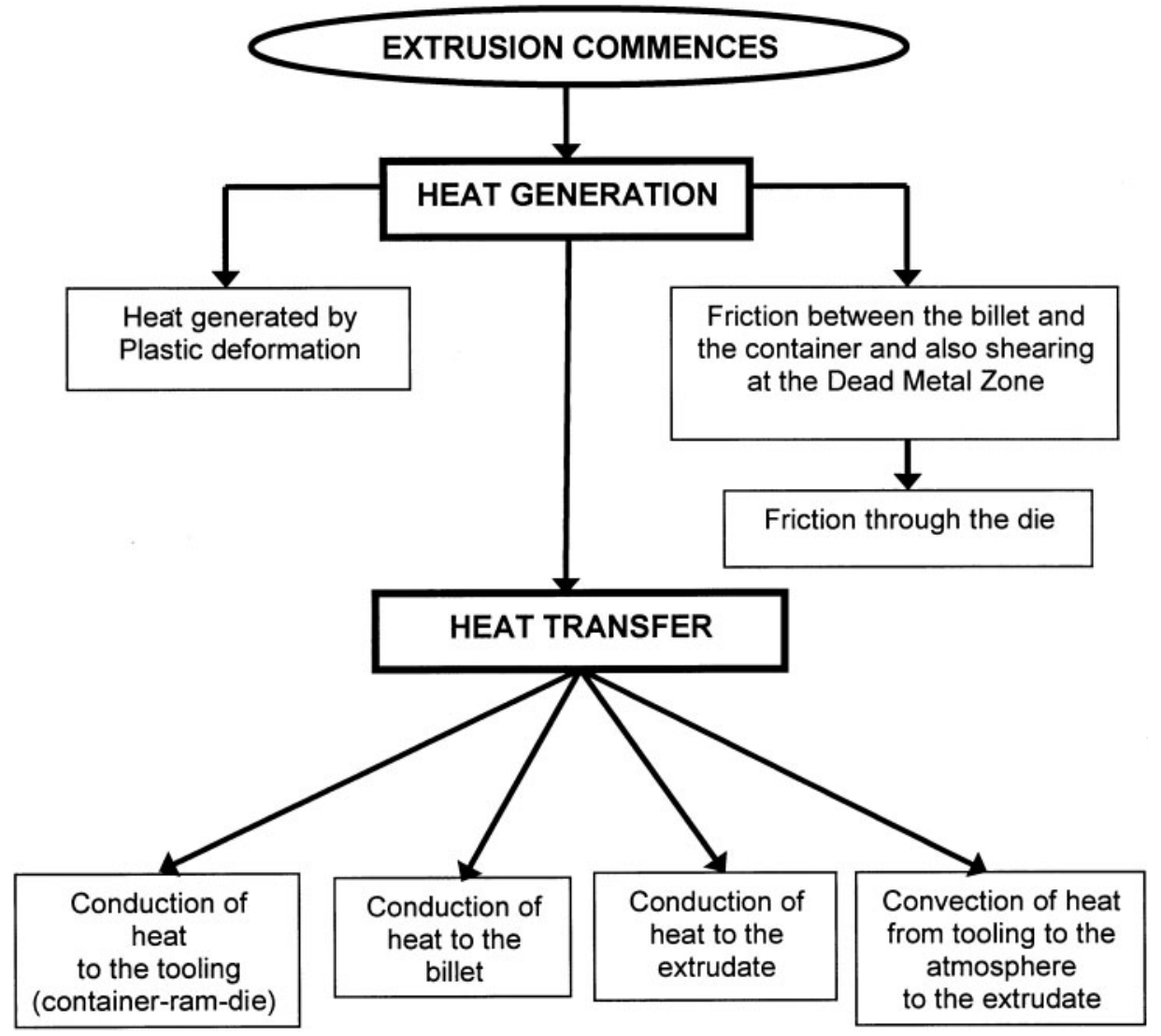

\section{Heat balance during extrusion process}

extrusion process for aluminium alloys can be regarded as lying between limits set by inherent stiffness (growing stiffness), even at some elevated temperatures, on the one hand, and the maximum temperature that can be tolerated during the process on the other. ${ }^{2}$

Temperature rise and temperature distribution during extrusion have been investigated by many researchers. ${ }^{3-6}$ The temperature rise during extrusion depends on many parameters and consists of the individual processes outlined by Sheppard ${ }^{1}$ and shown in Fig. 1.

The temperature rise within the shear zone is a function of the heat generation due to deformation, heat conduction to the cooler material on either side of the deformation zone, and convective (heat transport by material elements leaving the deformation zone). Because of the occurrence of conductive and convective heat transfer, the deformation is not adiabatic. Estimation of the temperature increase is alloy dependent. Pure aluminium alloy with the lowest flow stress has the lowest temperature rise and hard aluminium alloys with the highest flow stresses, the highest.

Many analytical and semi-analytical methods such as slip line, integral profile, upper bound, and ideal work, methods are well established and have been discussed in several textbooks and scientific papers. Although the finite element method (FEM) technique offers great potential, care must be taken when applying the analysis to the hot extrusion of rate sensitive alloys. The accuracy of the results depends on the geometric definition of the tooling, accurate material data, and the governing boundary conditions between billet and tooling. These parameters are clearly extremely sensitive when attempting to simulate the extrusion process. The extrusion parameters (friction, heat transfer, etc.) are significantly influenced by the temperature gradients produced in the billet during transfer to the container, and after upsetting in the container. ${ }^{7}$ Previous workers ${ }^{8-12}$ when simulating the extrusion process, have not considered meshing the tooling (container and die), although the heat transfer at the tool/billet interface governs the temperature profile throughout the billet and tools during extrusion and, consequently, has a critical influence on the results. The most useful approach for an FEM simulation would thus be to include both the tooling and the billet in the calculation as discretised meshes. This would both provide a more exact description of the thermal conditions and take the elastic properties of the tools into account. The disadvantage of this approach is the substantially higher computation time required to solve the numerical equation systems.

Numerous temperature linked FEM models have been proposed. However, few give any experimental verification. Generic deformation models are available and a number of publications have used the French developed FORGE2 software. In general authors have not presented details of the temperature changes occurring, which questionably is the most important feature of the extrusion process but Dashwood and McShane $^{8}$ have presented details of temperature rises during the extrusion of 7075 alloy and compared them with experimental data. The temperature was not measured but the results agreed with observations made on the onset of cracking and the incipient melting point. Another two dimensional model by Grasmo et al. ${ }^{13}$ considering only the steady state, presented much experimental evidence to justify their model. Their 
model has been used in this paper in order to validate the predicted temperatures readings from FORGE2.

\section{FEM programs and formulations}

In this investigation, a commercial finite element package FORGE2 ${ }^{14-15}$ developed by Transvalor (France) was used to simulate the extrusion of aluminium alloys. Details of the data structure of the program are given elsewhere. ${ }^{16}$

The constitutive equation is that developed by Sellars and Tegart ${ }^{17}$ and subsequently modified by Sheppard and Wright ${ }^{18}$ to yield the steady state flow stress $\bar{\sigma}$ using the Zener-Hollomon equation

$$
Z=A[\sinh (\alpha \bar{\sigma})]^{\mathrm{n}}=\stackrel{\bullet}{\bar{\varepsilon}} \exp \left(\frac{\Delta H}{G T}\right)
$$

from which

$$
\bar{\sigma}=\frac{1}{\alpha} \operatorname{Ln}\left\{\left(\frac{Z}{A}\right)^{1 / \mathrm{n}}+\sqrt{\left(\frac{Z}{A}\right)^{2 / \mathrm{n}}+1}\right\}
$$

in which $Z\left(\mathrm{~s}^{-1}\right)$ is termed the temperature compensated strain rate. The Arhenius term indicates that hot working is a thermally activated process ${ }^{19}$ with $\Delta H$ $\left(\mathrm{kJ} \mathrm{mol}^{-1}\right)$ as the activation energy for deformation, $\overline{\dot{\varepsilon}}$ $\left(\mathrm{s}^{-1}\right)$ is the mean equivalent strain rate, and $G$ $\left(8.314 \mathrm{~J} \mathrm{~mol}^{-1} \mathrm{~K}^{-1}\right)$ is the universal gas constant. A $\left(\mathrm{s}^{-1}\right), \alpha\left(\mathrm{m}^{2} \mathrm{MN}^{-1}\right)$ and $n$ are constants within the extrudable temperature range; $n$ is generally assumed to be a measure of the strain rate sensitivity and $\alpha$ appears to be a constant describing the transition from power to exponential relationships for the flow stress.

We should note that each of the parameters $\Delta H$, and $\alpha$ are interrelated and if, as is usually the case, multiple regression is employed to obtain the values it is important to ensure that these values are roughly representative in equation (1), we know that $\Delta H$ should have a value of $155000 \pm 15000\left(\mathrm{~kJ} \mathrm{~mol}^{-1}\right)$, this being the value for self bulk diffusion in aluminium.

The constitutive equation is incorporated into the solution by programming the user subroutine.

In the simulation of the extrusion process, the friction coefficient has a great effect on the computed load and the temperature evolution. ${ }^{7}$ In addition it affects the computed results, such as material flow, microstructural evolution and the product surface quality. Friction conditions at the billet/tool interface are known to affect the flow paths of the material at the container and through the die by changing the extrusion parameters, loads, stresses and surface quality.

\section{FEM models and source of experimental data}

The chemical compositions of the alloys used in this investigation are shown in Table 1. All the experimental data are extracted from the literature. ${ }^{20}$ The data describing the material behaviour available to the authors were obtained using torque--twist data from

Table 1 Chemical compositions of AA2024, ${ }^{1}$ wt-\%

\begin{tabular}{lllllllll}
\hline Alloy & Al & $\mathrm{Cu}$ & $\mathrm{Si}$ & $\mathrm{Mn}$ & $\mathrm{Mg}$ & $\mathrm{Fe}$ & $\mathrm{Ti}$ & $\mathrm{Zn}$ \\
\hline AA2024 & Bal. & $3.7-4.5$ & 0.15 & $0.15-0.8$ & $1.2-1.5$ & 0.2 & 0.15 & 0.25
\end{tabular}

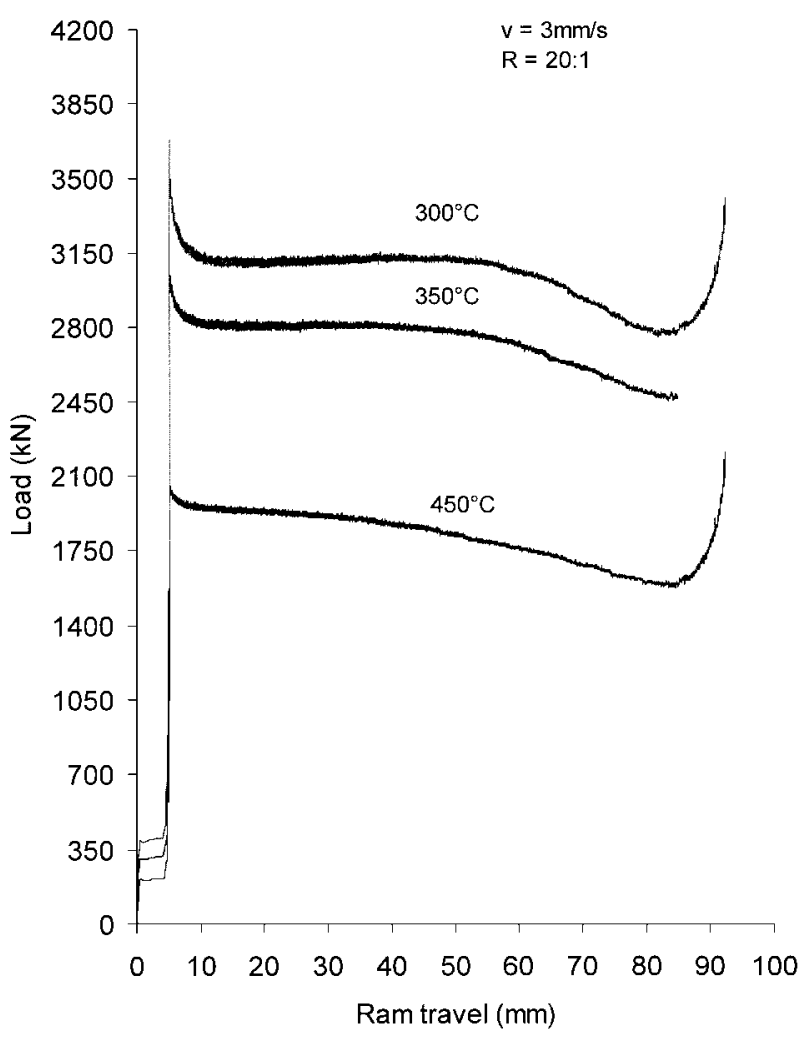

2 Ram load versus ram displacement (AA2024)

torsion tests and optimised to obtain the form of equation (1). The input data for the simulation are summarised in Table 2. All experimental details are given in Ref. 16.

\section{Results and discussion \\ Load-displacement diagram}

Load-displacement curves for direct extrusion of AA2024 are shown in Fig. 2. The stages preceding (i.e. upsetting) the peak load and until the so called quasistatic stage is reached is shown in Fig. 3. The figure shows the different stages that take place in the deformed material during the extrusion process. The locations selected for examination in Fig. 2 are shown in the form of a sequence of illustrations of the shear stress in Fig. 4.

Before extrusion can proceed, the billet must be inserted into the container and to facilitate entry there is generally appreciable clearance between the two. Thus initially the only contact of the billet with the tools is at the die face. The necessary force to be applied to cause the billet to fill the clearance is affected predominantly by the nature of the material and the manner in which its properties are affected by the temperature, i.e. material flow stress and the rate at which the work is carried out. The first effect of pressure at this stage is thus to compress or upset the billet into firm contact with the

Table 2 Rheology data input used for computer simulation ${ }^{1}$

\section{Flow stress data}

\begin{tabular}{lllll}
\cline { 2 - 5 } Alloy & $\alpha$ & $n$ & $\Delta H$ & $\ln (\boldsymbol{A})$ \\
\hline AA2024 & 0.016 & 4.25 & 148880 & 19.6 \\
\hline
\end{tabular}




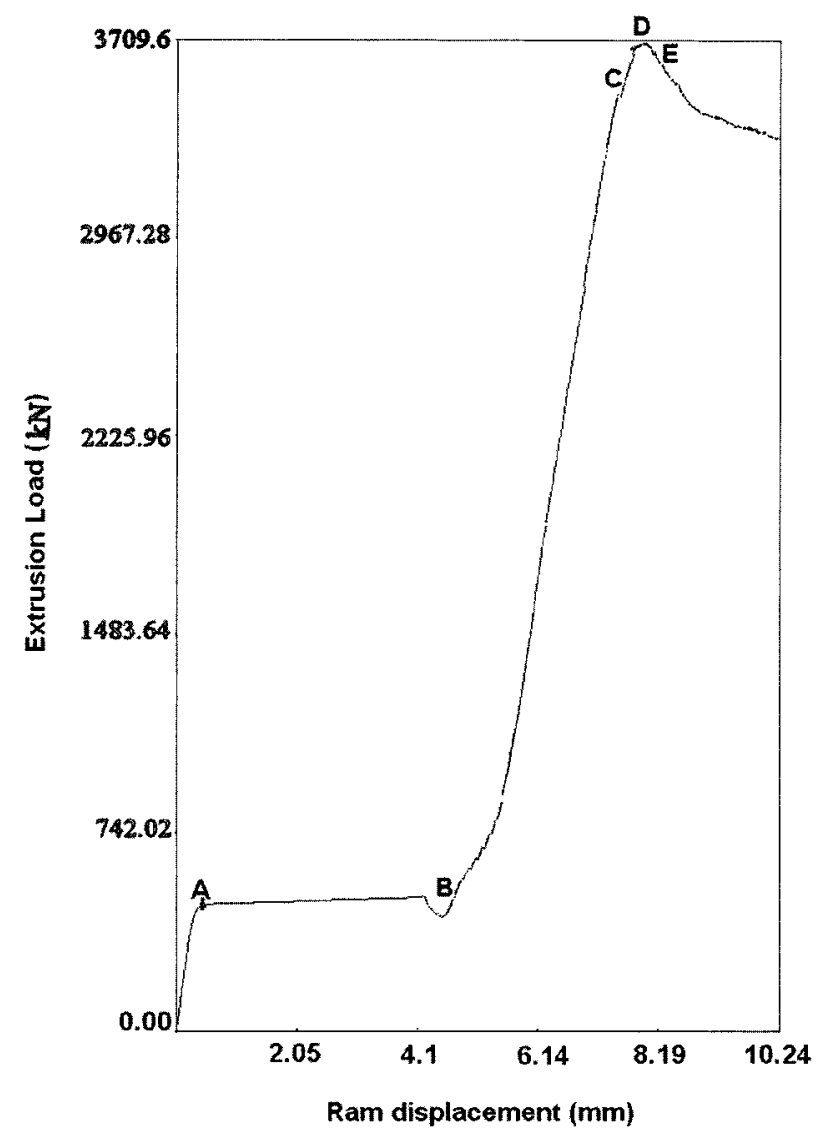

3 Locations preceding the peak load and until the so called quasistatic stage selected for examination in Fig. 2 cylinder wall as shown in Fig. $4 a$, corresponding to location A in the load-displacement diagram of Fig. 3. At this stage there is no significant deformation except at the region adjacent to the die entry, where some deformation may be detected. Deformation elsewhere in the billet is not apparent at this stage as indicated in Fig. $4 a$. When the billet is further compressed into the container localised deformation at the container wall and die entry is observed as shown in Fig. $4 b$. The location $\mathrm{B}-\mathrm{C}$ in Fig. 3 is characterised by a rapid increase in pressure and an extension of the main deformation zone into the back of the billet. At this stage a very small amount of extrusion takes place (location B-C) as illustrated in Fig. 4c. At commencement of the peak pressure region $(\mathrm{C}-\mathrm{D})$, a significant amount of extrudate material has already passed through the die land, which agrees with the observations made by Sheppard and Tutcher. ${ }^{21}$ However, the dead metal zone (DMZ) and main deformation zone are not fully established until the peak load reaches location D in Fig. 3, as shown in Fig. 5 (DMZ formation). During this stage, shearing of the billet at the container wall becomes apparent and a full deformation zone is established. The deformation zone is not stationary, the billet deforms plastically while the shear forces are operating, which promotes the burnishing effect at the DMZ/billet interface, necessary to obtain a satisfactory surface.

Once the peak is reached, the end of location D (Fig. 3) is characterised by an abrupt fall in pressure, which agrees with the observations first reported by Castle and Sheppard, ${ }^{3}$ followed by a more gradual

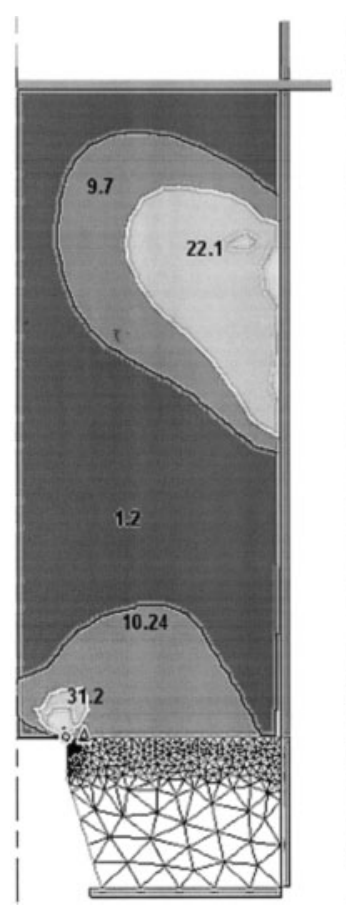

(a)

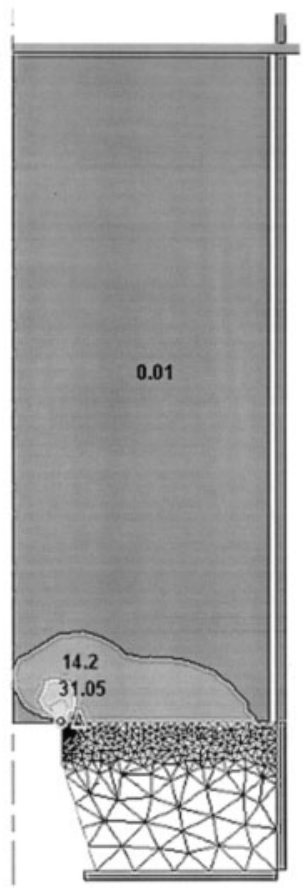

(b)

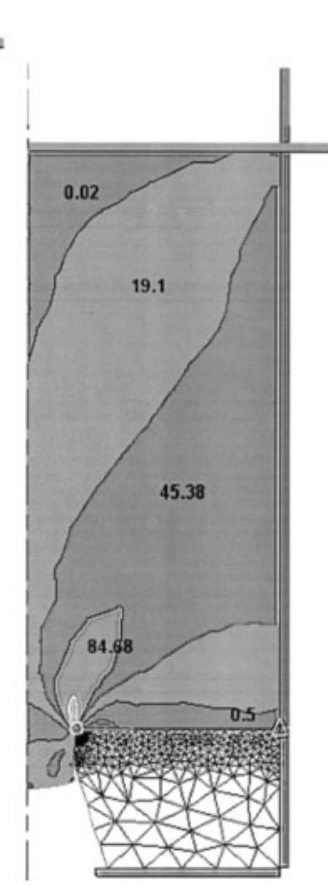

(c)

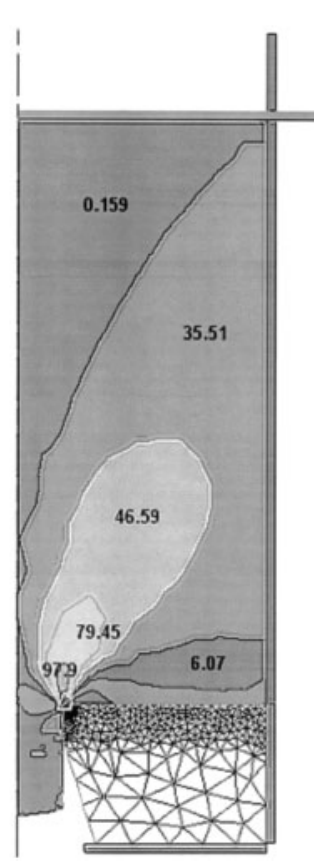

(d)

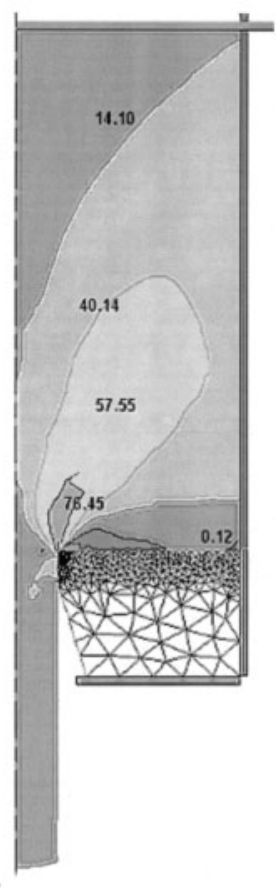

(e)

a location A in Fig. 3; showing deformation only at die entry; $b$ location A-B in Fig. 3; the billet is further compressed to fill container, localised deformation at die entry and container; $c$ location B-C in Fig. 3; showing extension of deformation zone into back of billet and commencement of extrusion; $d$ location C-D in Fig. 3; at the peak pressure region. Extrusion proceeds but the low values of stress suggest that extrusion structure remains as in the cast billet; $e$ location D-E in Fig. 3; the peak pressure region, the deformation zone, and the DMZ are fully established at the end of this stage

4 Deformation patterns during an extrusion cycle represented by the shear stresses in $\mathrm{MPa}\left(v=3 \mathrm{~mm} \mathrm{~s} \mathrm{~s}^{-1}\right.$, initial temperature $=300^{\circ} \mathrm{C}$ ) 


\section{Velocity profile illustrating formation of DMZ after peak pressure region}

decrease as the billet length decreases. The gradual decrease in the pressure after the maximum pressure has been established is caused by the temperature rise generated during the extrusion cycle. This decrease is more pronounced as the stress level increases. The steady state is established. The reduction of pressure during this stage is further aided by the decreasing length of the billet and the associated reduction in container/billet friction. The difference between the maximum and steady state pressure can be attributed to the force required to setup the dead metal zone and initiate the material flow through the die. The end of the extrusion cycle is characterised by a sharp increase in pressure as shown in Fig. 2, and is an indication of the discard length necessary.

\section{Temperature evolution}

During the extrusion process, the exit temperature is affected in by many parameters, including initial billet temperature, extrusion speed, extrusion ratio, mechanical and thermal properties of the billet material, and friction between the billet/die/container. Even the extrusion of simple rods is a complex process involving highly inhomogeneous deformation and high strain rate. The heat generated by the plastic deformation and friction significantly affects the mechanical properties of the deforming material, thereby increasing the temperature of the extrudate, and in turn affecting its microstructure and mechanical properties. The increase in temperature also affects the surface quality of the extrudate, which is of prime importance in many industrial extrusion processes, and is as important as the mechanical properties. Because extrusion is a non-linear process involving high inhomogeneous deformation and high strain rate, it is difficult to predict the exit temperature analytically.

It is recognised that during extrusion the deformation energy is converted into heat, thereby increasing the temperature of the extrudate and in turn affecting the microstructure and mechanical properties. The increase in temperature also affects the surface quality of the extrudate. The present investigation focuses on the evolution of temperature in the billet during the extrusion cycle.

\section{Model validation}

Temperature measurements of Grasmo's ${ }^{13}$ model were conducted on AA6060 alloy by inserting eight thermocouples in which two were fitted very close to the die surface (thermocouple 7). The model has been used in this investigation in order to validate the predicted temperature readings from FORGE2. The experimental details used are summarised in Table 3.

The results of their temperature reading are shown in Fig. 6. The figure shows the experimental and simulation temperature evolution at four different locations with ram travel.

The experimental measurements are represented by curves characterised by linked points. An extrusion using Grasmo's data in Table 3 has been simulated and applied in FORGE2. The predicted temperature results at thermocouple 7 are shown in Fig. 7.

Close agreement was found between the experimental and simulation results. However, small but acceptable deviations from the experimental results can be seen. This small variation between the measured and calculated temperature may be caused by the die bearing length used in the experimental model, which appears to be zero. This is practically impossible and we must assume that some small land length existed. It is still not desirable to use such a die using the FEA technique to simulate a process such as extrusion, especially if Lagrangian techniques for meshing and remeshing are adopted in the software logarithm, i.e. FORGE2. To overcome this problem, the model simulation conducted in this investigation has a $1.5 \mathrm{~mm}$ bearing length with a $0.5 \mathrm{~mm}$ radius at the re-entrant corner. This should have no effect on the predicted temperature evolution. However, Grasmo did explain that there may have been some uncertainty in the placement of the thermocouple and of the die and container properties. Nevertheless the agreement between the simulation and the experimental results was satisfactory and demonstrates that the FORGE2 software can predict temperature changes during the extrusion cycle.

It is appropriate at this point to draw attention to some of the limitations of the simulation in the present model apart from the die bearing length. The major limitation was the amount of computing time necessary for simulation of the model. It required more than 10 days $(251 \mathrm{~h})$ on a dual processor $(1.7 \mathrm{MHz})$ workstation to extrude $1 / 3$ of the billet length. A vast number of elements were generated during meshing and remeshing of the billet and formation of the extrudate. This of course has a great effect on the number of equations to be solved and the time to solve them, since small time steps of 0.005 were used during the simulation to ensure

Table 3 Grasmo's model ${ }^{13}$

\begin{tabular}{|c|c|c|c|c|c|}
\hline Material & $\begin{array}{l}\text { Billet } \\
\text { temp., } \\
{ }^{\circ} \mathrm{C}\end{array}$ & $\begin{array}{l}\text { Container } \\
\text { emp., }{ }^{\circ} \mathrm{C}\end{array}$ & $\begin{array}{l}\text { Ram } \\
\text { speed, } \\
\mathrm{mm} \mathrm{s}^{-1}\end{array}$ & $\begin{array}{l}\text { Billet } \\
\text { length, } \\
\mathrm{mm}\end{array}$ & $\begin{array}{l}\text { Diameter, } \\
\text { billet-extrudate, } \\
\mathrm{mm}\end{array}$ \\
\hline AA6060 & 480 & 450 & 5 & $302 \cdot 5$ & $97-15 \cdot 8$ \\
\hline
\end{tabular}




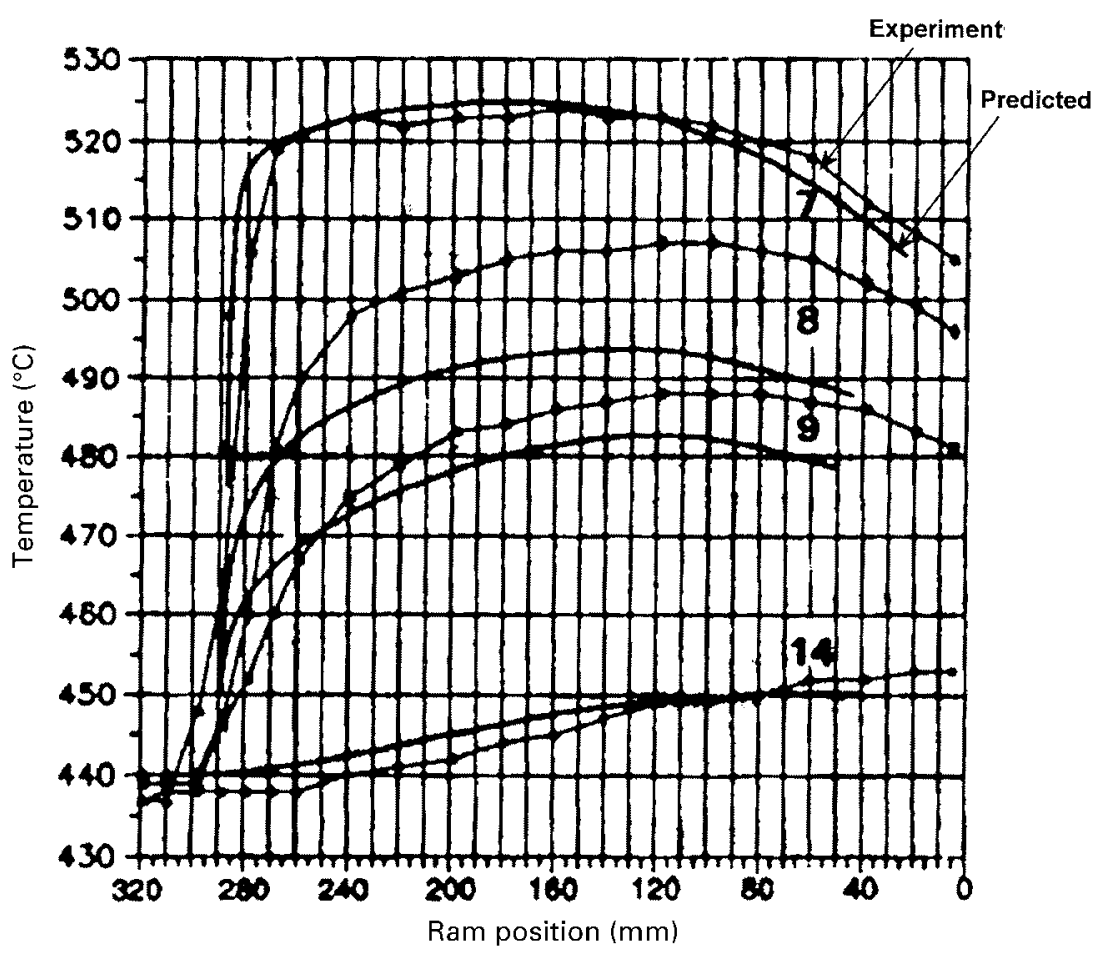

6 Temperature changes according to Grasmo et al:: ${ }^{13}$ experimental curves denoted by linked points

accuracy. Consequently, the simulation was stopped just after $1 / 3$ of the billet was extruded and enough data were available for discussion. One can safely conclude that close agreement between experimental and simulation results was found. However, small deviations from the experimental results can be observed.

\section{Temperature changes during extrusion}

The simulation models used to investigate the temperature evolution during extrusion are similar to the models used to investigate the pressure-displacement diagram shown Fig. 3 (AA2024, $R=20: 1$ and $v=3 \mathrm{~mm} \mathrm{~s}^{-1}$ ).

The temperature evolution during a complete extrusion cycle is shown in Fig. 8. The extrusion pressure is significantly influenced by the temperature gradients produced in the billet after upsetting in the container. Therefore it is more useful to investigate the temperature evolution during the extrusion process in a similar manner to the pressure-displacement curve.

As expected the temperature rise is significant at low initial billet temperature. This is because at lower temperatures (i.e. $300^{\circ} \mathrm{C}$ ), a greater amount of work is required to achieve steady state, and the temperature

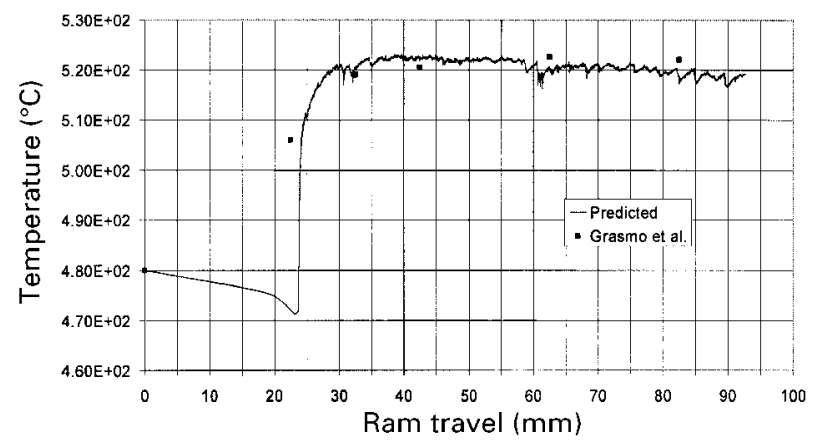

7 FORGE2 temperature prediction versus Grasmo's experimental measurements at thermocouple 7 rise in the material will be greater as a result of such work. As the initial temperature increases, the temperature rise decreases due to the decrease in work done because of lower flow stresses. The rate of temperature change in the deformed material is directly proportional to the resistance to deformation; at $450^{\circ} \mathrm{C}$ the maximum temperature rise was $45 \mathrm{~K}$ compared to $83 \mathrm{~K}$ at low temperature (Table 4). The events occurring after the peak pressure and maximum temperature have been established are also a function of ram speed, as shown in Fig. 9. An interesting feature in Fig. 9 is the increase in temperature towards the end of the extrusion cycle. As the ram, which has an initial temperature of $200^{\circ} \mathrm{C}$, approaches the die, which has an initial temperature of $300^{\circ} \mathrm{C}$ plus an increase of temperature during deformation $\left(\Delta T_{\text {die }}\right)$, a significant amount of heat is transferred in the direction opposite to the extrusion, heating the dummy block.

The temperature evolution in the billet (initial temperature $350^{\circ} \mathrm{C}$ ) as the extrusion proceeds from the start and until quasistatic steady state, is shown in

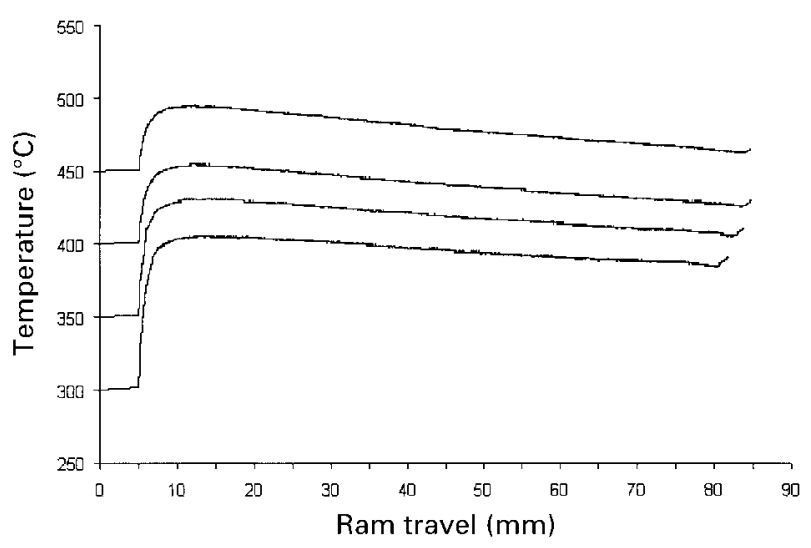

8 Temperature evolution cycle during the extrusion of AA2024 alloy, $R=20: 1$ and $v=3 \mathrm{~mm} \mathrm{~s}^{-1}$ 


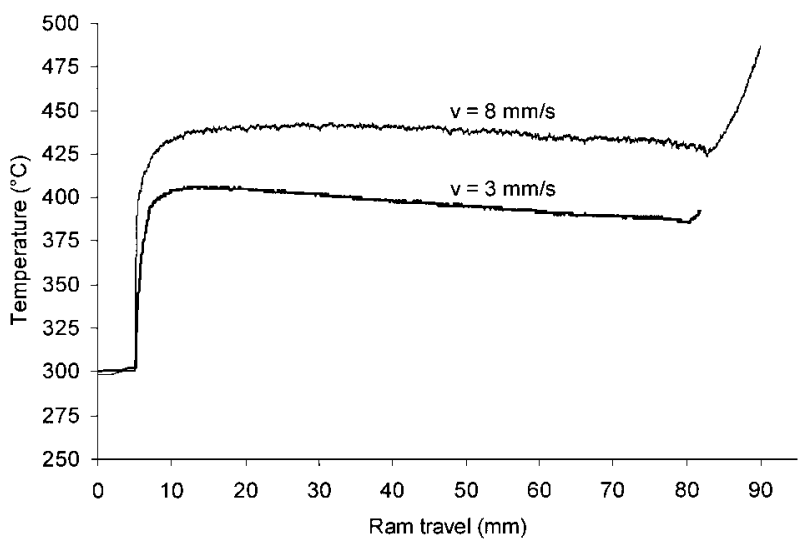

9 Effect of ram speed on temperature evolution during the process

Fig. 10. Heat transfer occurs as soon as the billet contacts the tools. As the billet is upset to fill the container, a small loss of temperature from the billet surface to the die face and the container wall is encountered, as shown in Fig. 10a. This stage corresponds to location A in Fig. 3 when the billet is fully compressed into the container. Obviously the maximum temperature remains equal to the initial billet temperature and is located at the centre of the billet since no deformation is apparent elsewhere at this stage. However, the minimum temperature in the billet material is located along the billet/tool interface. This location corresponds to the first point of contact of the billet's surface with the tools after first upsetting the billet. It is interesting to note that following the events
Table 4 Predicted temperature rise

\begin{tabular}{lc}
\hline Initial billet temperature, ${ }^{\circ} \mathbf{C}$ & Temperature rise, $\mathbf{K}$ \\
\hline 300 & 106 \\
350 & 81 \\
400 & 55 \\
450 & 45 \\
\hline
\end{tabular}

occurring as shown in the pressure-displacement diagram of Fig. 3 at location B when extrusion commences, the tooling continues to act as a heat sink to the billet surface and in particular at the die front, as shown in Fig. 10b. However, as the figure also illustrates, a small increase in the billet temperature is observed at the die entrance at this stage. This rapid increase in temperature continues throughout the peak pressure region and beyond as shown in Fig. $10 c$ at the peak pressure and Fig. $10 d$ at the end of peak pressure region. This increase in billet temperature is a consequence of the production of heat by deformation of the billet as it breaks through the die orifice, proceeding to the front of the die in the deformation zone. Accordingly heat is conducted from the deformation zone towards the rear of the billet and results in an increase in overall temperature. The steady state region is characterised by a slow increase in temperature as shown in Fig. 10e. This is as a result of less heat being generated by mechanical work done due to the thermally softened billet and the decrease in billet length.

Much of the heat generation occurs at the DMZ/ deformation zone shear region, and results in a steep rise in temperature as the material approaches the die land.

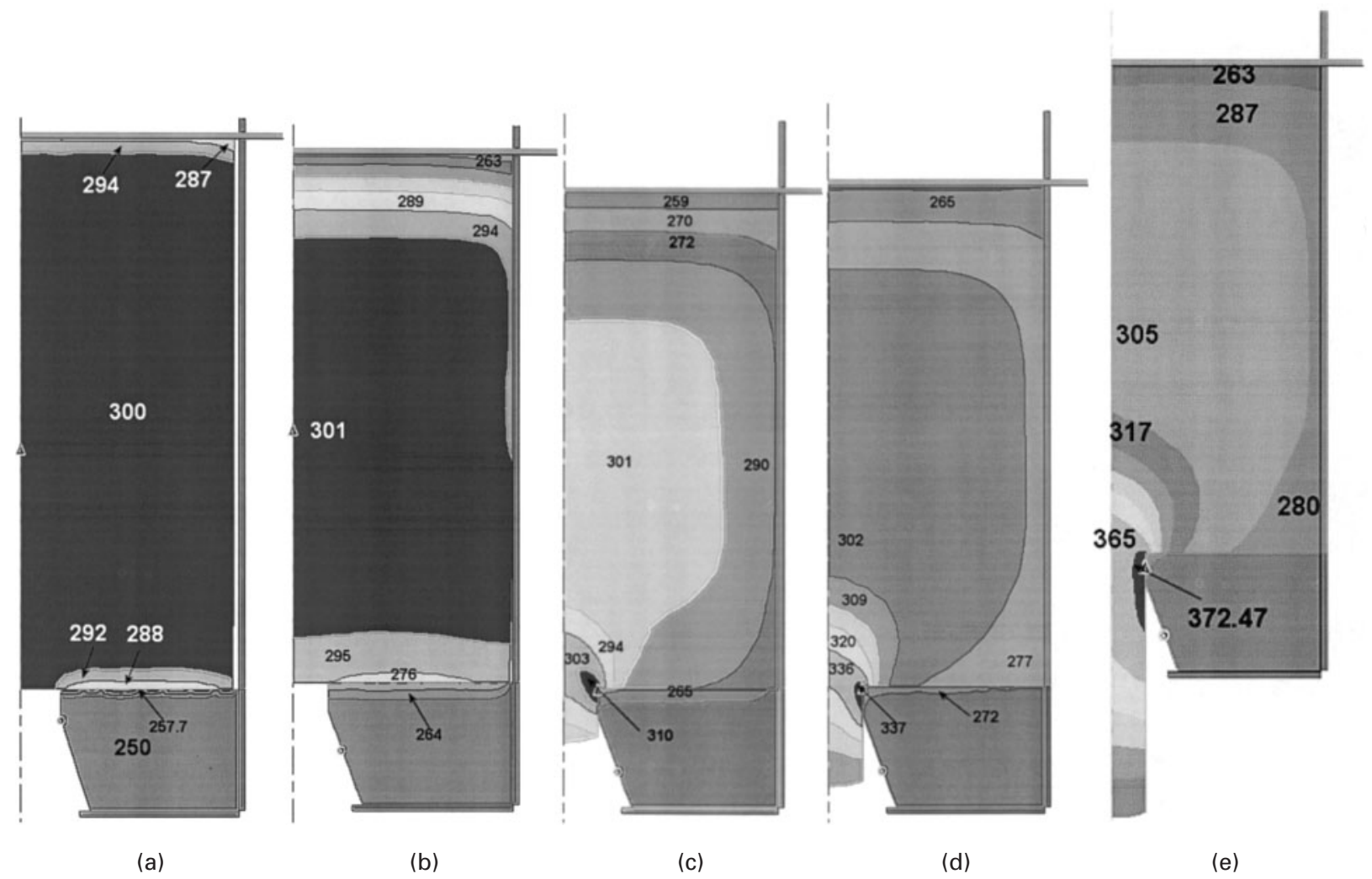

a location A start of upsetting; $b$ location B end of upsetting; $c$ before peak pressure; $d$ at peak pressure; $e$ quasistatic deformation

10 Temperature events occurring throughout the extrusion cycle defined in Fig. 3: initial billet temperature $300^{\circ} \mathrm{C}$ 


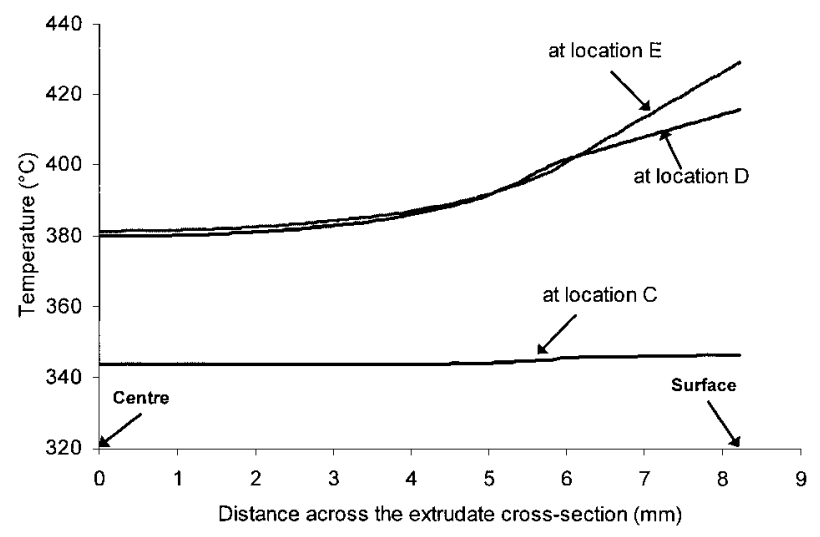

11 Temperature evolution across extrudate cross-section at a location between $C$ and $E$ in Fig. 3

The temperature in the extrudate material emerging through the die orifice varies significantly across the extrudate cross-section, as shown in Fig. 11. This increase is more significant at the edge of the extrudate surface than at the centre. This increase in temperature is due to the higher strain rate prevailing at the die entrance and the friction at the extrudate die bearing/interface, indicating that the material at the periphery is derived from the heavily worked shear zones, as shown in Fig. 12. Finally, conduction commences as soon as the extrudate leaves the die and contacts ambient temperatures.

Throughout the location A-D in Fig. 3 , at $0.5 \mathrm{~mm}$ from the interface, the surface temperature at the billet/ container interface remains lower than the initial billet temperature $\left(350^{\circ} \mathrm{C}\right)$, as shown in Fig. 12 , with a slow increase as the billet is further upset. Furthermore, it is not until the steady state region that a significant increase is observed at the billet/surface interface, thus showing that heat generated by deformation contributes significantly towards the overall temperature increase than does the heat generated at the interface (billet/ container).

\section{Conclusions}

1. FEM has been successfully applied to model the deformation patterns in the load/displacement traces and temperature evolution during the extrusion cycle.

2. Experimental and simulated temperature rises are shown to be in good agreement.

3. The initial stages of deformation, where the billet is primarily affected by the flow stress of the material and the rate at which the work is carried out, proved to be of some significance in dictating the material flow distribution during the extrusion process.

\section{Acknowledgements}

The authors would like to express their thanks to Dr J. Subramaniyan for the use of the results of his experimental work. The provision of facilities by Bournemouth University is also gratefully recognised.

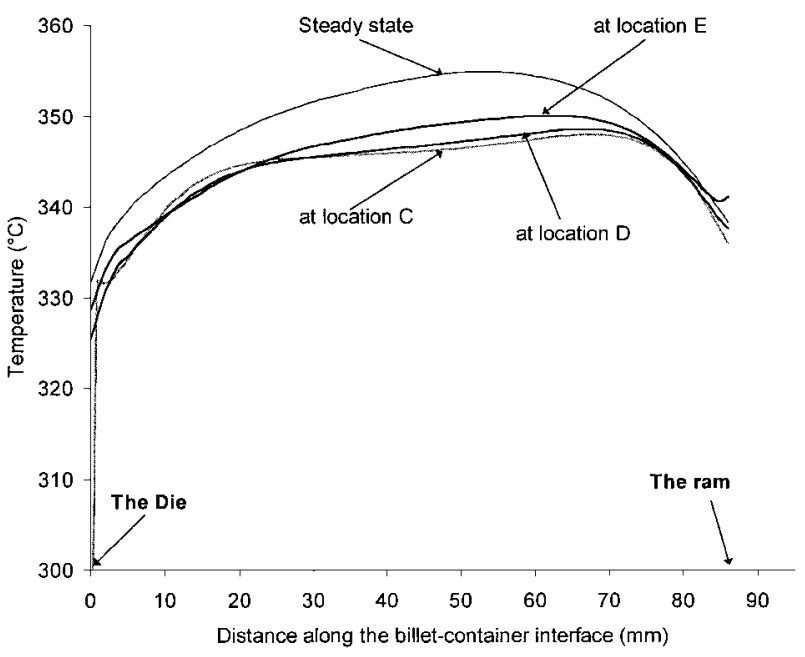

12 Billet surface temperature $0.5 \mathrm{~mm}$ from the interface container wall at location C-E and steady state in Fig. 3

\section{References}

1. T. Sheppard: 1999 'Extrusion of aluminium alloys'; 1999, Dordrecht, The Netherlands/Boston, MA, USA, Kluwer Academic Press.

2. T. Sheppard: Mater. Sci. Technol., 1993, 9, 313-318.

3. A. F. Castle and T. Sheppard: Mater. Sci. Technol., 1976, 3, (10), $465-475$.

4. A. F. Castle : 5th Int. Seminar on 'Aluminium extrusion technology', Chicago, IL, USA, May 1992, Aluminium Extruders Council and the Aluminum Association, 181-185.

5. P. K. Saha: Wear, 1998, 218, 179-190.

6. P. K. Saha and R. K. Ghosh: Indian J. Technol., 1979, 17, (7), 264 268.

7. I. Flitta and T. Sheppard: Mater. Sci. Technol., 2003, 19, 837846.

8. R. J. Dashwood, H. R. McShane and A. Jackson: Proc. 6th Int. Seminar on 'Aluminium extrusion technology', Chicago, IL, USA,. May 1996, The Aluminum Association, 331-339.

9. X. Velay, X. Duan and T. Sheppard: Mater. Sci. Forum, 2003, 5, 426-432.

10. X. Duan and T. Sheppard: TMS Annual Meeting, 2003, 99-108.

11. X. Duan and T. Sheppard: TMS Annual Meeting, 2003, 289.

12. X. Duan and T. Sheppard: Computat. Mater. Sci., 2003, 27, (3), $250-258$.

13. G. Grasmo, K. Holte, S. Stren, H. Valberg, R. Flatval, L. Hanssen, M. Lefstad, O, Lohne, T. Web, R. Ørsund and J. Herberg: Proc. 5th Int. Seminar on 'Aluminium extrusion technology', Chicago, IL, USA, May 1992, The Aluminium Association, pp. 367-376.

14. J.-L. Chenot et al.: Int.. Conf. on' Forging and related technology', (ICFT'98), 113-122; 1998, Bury St Edmonds, Suffolk, UK, Professional Engineering Publishing.

15. 'FORGE3 Version 6.2 and FORGE2 V2.9 software manual', Sophia Antipolis, France, Transvalor SA,

16. I. Flitta and T. Sheppard: Mater. Sci. Technol., in press.

17. C. M. Sellars and D. Tegart: Int. Metall. Rev., 1972, 17, 1-24.

18. T. Sheppard and D. Wright: Met. Technol., 1979, 6, (6), 215223.

19. T. Sheppard and A. Jackson: Mater. Sci. Technol., 1997, 13, 203209.

20. J. Subramaniyan: 'Extrusion of 2024 aluminium alloy sections', PhD thesis, Imperial College, London University, 1989.

21. T. Sheppard and M. G. Tutcher: Met. Sci., 1980, 14, (12), 579589. 